\title{
Virtual environments in educational networks
}

\author{
Christos Bouras, Agisilaos Konidaris and Afrodite Sevasti \\ Computer Technology Institute-CTI, Kolokotroni 3, 26221 Patras, Greece.bouras@cti.gr \\ Department of Computer Engineering and Informatics, University of Patras, Greece. \\ Department of Computer Engineering and Informatics, University of Patras, Greece.
}

Keywords: virtual environments, educational networks, network services

\begin{abstract}
The field of Virtual Environments (VEs) is rapidly evolving into a new means of communication and accessing information, likely to overcome many existent technologies. However, being a new field makes the design and implementation of educational VEs an important aspect for scientific research in their educational potentials and the exploitation of existent technologies. New technologies in the field of VEs have appeared the establishment and combination of which, is yet to be investigated. This paper makes an effort to approach the issue of developing educational VEs introducing new aspects in the issues of interface, interaction with the user and functionality.
\end{abstract}

\section{INTRODUCTION}

These days, the use of Information Communication Technologies (ICT) has become essential to every learning procedure. New means are making themselves available to the teachers in order to make it easier for them to teach and make their knowledge available to their students. One of the most promising and most recent technologies in this field is the implementation of Virtual Environments (VE).

The term Virtual Environment is used to represent a computer-based interface that simulates ordinary every day activities and provides wellknown computer and network services through it. The way that VEs can play a role in educational procedures is starting to appear. By using a virtual environment instead of a contemporary interface, you can easily help people (students and teachers in our case) access all of the available computer and network services without them being expert computer users. Thus, a VE is

\footnotetext{
The original version of this chapter was revised: The copyright line was incorrect. This has been corrected. The Erratum to this chapter is available at DOI: 10.1007/978-0-387-35499-6_29 
the best candidate to play the role of the intermediary between basic and advanced services and the inexperienced end user.

\section{INTERNATIONAL PROJECTS}

The development of educational VEs has been the goal of many projects around the world. We attempt to show the present situation on VE development with this indicative list of projects (Table 1).

Table 1. Educational VEs in projects around the world

\begin{tabular}{|c|c|c|}
\hline Project Name & $\begin{array}{l}\text { Participating } \\
\text { Countries }\end{array}$ & Goals \\
\hline VES [VES98] & $\begin{array}{l}\text { Austria, Italy, } \\
\text { Greece }\end{array}$ & $\begin{array}{l}\text { The development of a } \\
\text { comprehensive resource of teaching } \\
\text { material for secondary school } \\
\text { education using virtual user } \\
\text { interfaces. }\end{array}$ \\
\hline $\begin{array}{l}\text { ON LIVE } \\
\text { (ON Line Interactive } \\
\text { Virtual Educator) }\end{array}$ & $\begin{array}{l}\text { European } \\
\text { Countries }\end{array}$ & $\begin{array}{l}\text { Contact for groups of teachers in } \\
\text { different schools with an innovative } \\
\text { telematic service, permitting the } \\
\text { students to learn thanks to a } \\
\text { personalised "educator" in the form } \\
\text { of an 3D character close to the } \\
\text { learning thematic desired. }\end{array}$ \\
\hline $\begin{array}{l}\text { SAELN (Students Across } \\
\text { Europe Language } \\
\text { Network) }\end{array}$ & $\begin{array}{l}\text { Germany, } \\
\text { France, Spain, } \\
\text { England }\end{array}$ & $\begin{array}{l}\text { The development of a virtual } \\
\text { interactive language and culture } \\
\text { education resource for students to } \\
\text { communicate with each other. }\end{array}$ \\
\hline $\begin{array}{l}\text { VIRLAN (Foreign } \\
\text { Language Virtual } \\
\text { Environment for Primary } \\
\text { School Children) }\end{array}$ & $\begin{array}{l}\text { UK, Finland, } \\
\text { Germany, and } \\
\text { Greece }\end{array}$ & $\begin{array}{l}\text { Creating a virtual world in which } \\
\text { children can learn by interacting } \\
\text { with foreign children as if they were } \\
\text { physically present in the same place. }\end{array}$ \\
\hline $\begin{array}{l}\text { VRLEARNERS (Virtual } \\
\text { Reality Learning } \\
\text { Environment for Network } \\
\text { of Advanced Educational } \\
\text { Multimedia Resource } \\
\text { Centres, Museums and } \\
\text { Schools) }\end{array}$ & $\begin{array}{l}\text { European } \\
\text { Countries }\end{array}$ & $\begin{array}{l}\text { The use of advanced multimedia } \\
\text { technologies in the schools } \\
\text { environment and to promote co- } \\
\text { operation between educational } \\
\text { multimedia resource centres, cultural } \\
\text { institutions, educators, scientists and } \\
\text { schools with the aim to improve } \\
\text { learning and training systems in } \\
\text { Europe. }\end{array}$ \\
\hline $\begin{array}{l}\text { Quebec English Schools } \\
\text { Network }\end{array}$ & Canada & $\begin{array}{l}\text { The development of a virtual } \\
\text { classroom and a virtual staff room. }\end{array}$ \\
\hline $\begin{array}{l}\text { TIPP (Technology } \\
\text { Incentive Partnership } \\
\text { Program) }\end{array}$ & Canada & $\begin{array}{l}\text { Development of educational } \\
\text { resources that can be shared among } \\
\text { school boards across the province, } \\
\text { through virtual user interfaces. }\end{array}$ \\
\hline
\end{tabular}


The resulting idea from this survey is that the field of educational VEs' development is beginning to be realised as a very important tool in the educational procedure [VES-WP398]. VEs will soon become integrated in every educational process and will be considered a major breakthrough in education.

\section{DEVELOPMENT OF A VIRTUAL ENVIRONMENT}

There are certain basic concepts on which someone should rely in order to develop a fully functional educational virtual environment (Waters 1996; Turoff 1995). The basic characteristics of the design of an educational VE, as we propose them, must be the following (Earnshaw 1995).

- The VE that will be developed must be user friendly, that is, easy to use. Since the main goal that is to be achieved by developing the VE is the promotion of the educational procedure and since the users of the VE are mainly students this must be the fundamental characteristic of the VE.

- The VE should be simple and comprehensible in its concept (Stuart 1996; Weishar 1998). It must be able to give the user the ability to navigate easily inside it. This can be achieved by developing the VE in such a manner that it simulates environments that the user is used to, such as every day environments. The user must be presented with the capabilities of the basic and advanced network services but this presentation must give him the illusion that he has used them before even though he hasn't. For example the basic network service of sending email can be simulated in the virtual world by the use of an ordinary mailbox. The user will be given the ability to send email by just clicking on a virtual mailbox in the VE instead of having to use a much more sophisticated mail client.

- The VE should be equipped with the ability to provide help at any moment that the user might find it useful. Sometimes even though the developer is aiming at simplifying the network services provided as much as possible, the user might come to a situation where he will not know how to proceed or how to use certain object in the VE. In such a case the VE should be able to guide the user through the problem. There are several scenarios that can be selected for providing help. One is the provision of help whenever a user right-clicks on an object in the VE. Another is the constant provision of help in a separate browser frame. The second even though may seem elementary is much more efficient since it does not demand any action by the user in order to provide help.

- Our proposal for the architecture of the virtual environment is to follow a tree-like structure, where the first two levels will be handled by the 
virtual user interface and the other two will be handled by a combination of the services embedded in the user interface and some auxiliary browser frames. This architecture is apparent in Figure 1.

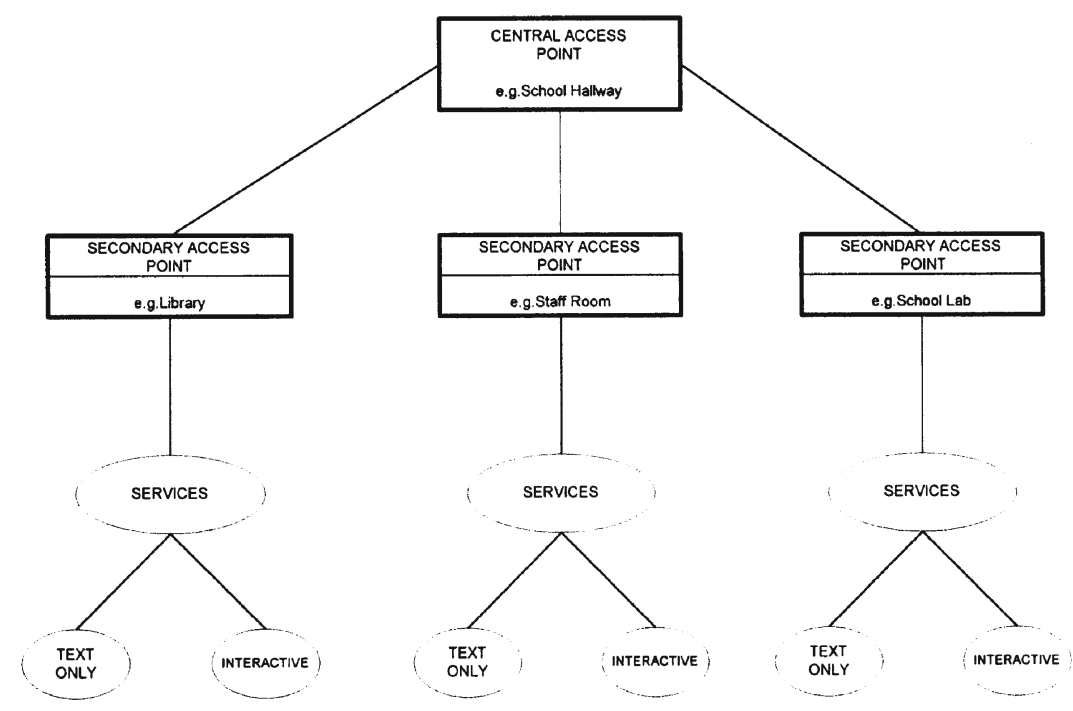

Figure 1 The proposed tree-like structure for the architecture of the virtual environment

\section{DESIGNING THE USER INTERFACE}

\subsection{Browser layout}

The educational VE that we propose, and that will be able to provide basic and advanced network services to inexperienced users such as students, will consist of three unequal frames into which the browser window will be divided. The VE will be shown in Frame 1. In Frame 2 we will provide constant help to the user and Frame 3 will be used to interact with the user (see Figure 2). Through Frame 3 the user will be able to pass information that will be required at some point from the VE and see the results of his actions. 


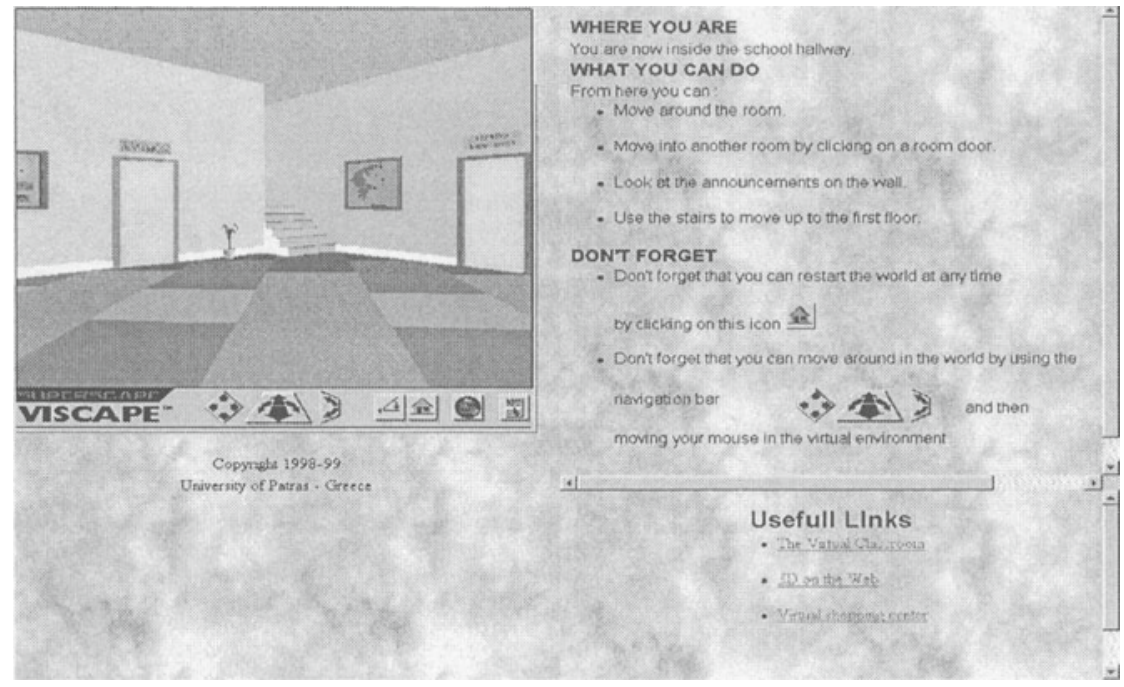

Figure 2. An instance of the central room of the school in the virtual user interface, with Frame 1 on the right, Frame 2 on the top left and Frame 3 on the bottom left of the browser window [VRT for Windows 98].

After the VE has been loaded the user will find himself in front of a big building that will be the virtual school. At this point the user can navigate around the school but he will not be offered any significant services. The user must make his way to the school door and enter in order to take advantage of the full potentials of the VE.

As soon as the user passes through the main school door he will find himself in the central room of the school (Figure 2) which resembles the school hallway. Around the room the user can see other doors that lead to other rooms. These are the staff room, students' room, library, computer laboratory and other rooms where specific lessons are supposed to be taught, such as Geography and History. The user at this point may select a door and enter into the room that he decides. The main room of the VE provides the certainty that the user is presented with all the abilities of the VE at once and he can choose at his convenience.

\subsection{The teacher room}

This room will address the user's need to access information concerning the school's teachers. Through symbolic assimilations, the user will be able to access a teacher's personal web page, if any, personal information about teachers and the lesson that they are teaching as well as perform trivial searching activities among the teaching staff. The user can also find out the 
lesson timetable of the school and exchange off-line messages with the teachers.

As the user enters this room he will find himself in front of a set of cabinets through which the subdivision of the school's directory service containing the teachers' entities will be provided. The searching procedure to be followed is: select the cabinet which holds the first letter (from A to Z) of the surname of the teacher to be found, click on the appropriate teacher's name from the ones beginning with the specific letter, which appear as hyperlinks in Frame 3 and then receive information on the teacher and the lessons that he teaches, on Frame 3 again. This information will be available in the form of a card (like a library card) which will consist of a photograph, information and several functionalities such as a button on which the user can click and send email to the teacher, by using Frame 3 again. At any moment the user will be able to return to the VE and recommence his trip.

The teacher room will also be equipped with a desk that will have an interactive book, containing the school timetable, and a computer on it. The computer will provide an alternative means for accessing the teachers' division of the directory service as if one was using a normal web based search. The user will be asked to input the information and receive the results of the search in Frame 3. A bulletin board in the teachers' room will contain any recent announcements concerning the school, for the user to read.

\subsection{Student room}

The student room will be very similar to the teacher room with some extra features. The user will be able to find a student of the school as described in the teacher room section, using the same two alternative approaches. The bulletin board will be enriched with announcements on student activities such as a school newspaper or maybe some sport activities.

\subsection{Library room}

The library room will simulate the environment of a real library (Figure 3 ). When the user enters he will find himself in front of libraries full of books. Above every section of the library the user will be able to see a sign that will indicate the category of the books that are below. When the user chooses a category he will be able to move towards the specific section of the library and look at the subsections of the specific category written on the selves. By clicking on a subsection the user will be able to see in Frame 3, information on all the books available in the school library that concern the specific subsection. 


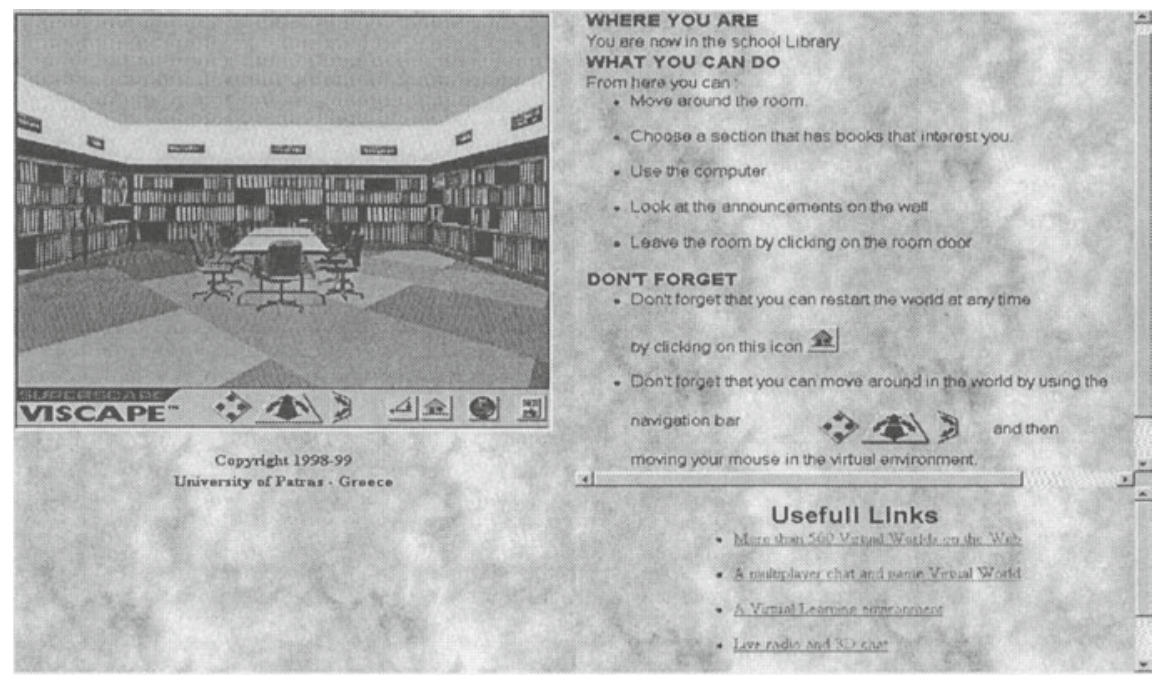

Figure 3. Instance of a specific room's user interface: The Library Room

The library room will also have a bulletin board where the user will be able to get information on the library working hours and where he can send email to contact the librarian.

\subsection{Laboratory room}

The lab room will be a simulation of the school lab. The user will be able to see desks with all of the school's equipment on them such as computers, faxes etc. By clicking on every piece of equipment the user will receive information on its configuration, its last use and, in some cases, use it by sending faxes and messages to the other users of the computers in the school lab, through Frame 3.

\subsection{Specific lesson rooms}

The specific lesson rooms will be dedicated to giving information about specific lessons that are taught at the school. These rooms will be divided into three sections.

- The library section that will be a subsection of the whole library and the user will be able to choose titles that concern only the specific lesson. The library will be the same as the one described in the library room section, only smaller.

- The computer section. This section will consist of a desk where the user will be able to use a computer to make queries concerning books on a specific lesson (depending on the room that he is in). There will also 
exist an information book, by clicking on which, the user will be able to receive other available on the Internet resources concerning the specific lesson, accessed by hyperlinks in Frame 3.

- The specific lesson section in form of a bulletin board, where the user will be able to see all the information concerning the specific lesson at the school. This information may be the timetable of the lessons, the teachers that teach the specific lesson and the subjects that the specific lesson covers.

The walls of the specific lesson rooms will be decorated with relevant pictures. For example the in the Geography room the user will be able to see maps, by clicking on which, he will be able to see the books that are available in the library about a specific geographical region.

\section{CONCLUSIONS - FUTURE WORK}

The basic concluding remark after designing and implementing the VE is its potentials are almost unlimited. Future work is suggested on the subjects of linking databases and making them co-operate with the virtual environment (Bouras 1998) as well as creating educational Distributed Virtual Environments (DVEs) (Snowdon et al. 1996). Both of the above will raise the functionalities of such environments to such a level that many established current technologies will become obsolete and be replaced (Schneiderman 1997).

It is important to mention that a VE, which integrates all the network services that are mentioned above, requires constant update and maintenance. The procedure of integrating all these services will surely be lengthy but the result will be a major breakthrough in the educational procedure.

The VE will help the educational community come much closer and will of course promote the exchange of ideas between different cultures. It can provide the forum for meetings and all types of communication.

\section{REFERENCES}

Bouras, C., Fotakis, D., and Philopoulos, A. (1998) A distributed virtual learning centre in cyberspace. Paper given at 4th International Conference on Virtual Systems and Multimedia, VSMM98, Gifu-Japan, 18-20 November 1998.

Earnshaw, R. J. and Vince, J. (1995) Computer graphics: Developments in virtual environment. London: Academic Press.

Schneiderman,B. (1997) Designing the user interface: Strategies for effective humancomputer interaction. Reading, United Kingdom: Addison-Wesley.

Snowdon, D., Greenhalgh, C., Benford, S., Bullock, A. and Brown, C. (1996) A review of distributed architectures for networked virtual reality. Research Development and Applications 2(1) 155-175. 
Stuart. R. (1996) The design of virtual environments. Blacklick, Ohio: McGraw-Hill.

Turoff, T. (1995) Designing a virtual classroom. Department of Computer and Information Science. New Jersey, New Jersey Institute of Technology.

VES (1998) The Virtual European School, ANNEX I - Project Programme, January 1998.

Der Buchhandel, Wirtschaftskammer Osterreich.

VES-WP3 (1998) D3.2 Technology Monitoring Report, August. Brussels:EU.

VRT for Windows (1998) User guide. Santa Clara, USA: Superscape.

Waters, R., Anderson, D., and Barrus, J. (1996) Diamond Park and Spline: A social virtual reality system with $3 D$ animation, spoken interaction and runtime modifiability. Cambridge, Massachusetts, Mitsubishi Electric Research Laboratory.

Weishar, P. (1998) Digital space: Designing virtual environments. New York: McGraw-Hill.

\section{BIOGRAPHIES}

Dr. Christos J. Bouras is the Head of Research Unit 1, Computer Technology Institute (CTI). His $\mathrm{PhD}$ is from the Computer Science and Engineering Department of Patras University. He is currently working in the area of networks, educational technology, telematics and new services. He is experienced in the design and analysis of networks and protocols, and their use for medicine and education. He has been in various research and development projects, including RACE and ADAPT. He has published a number of papers is a co-author of two books.

Agisilaos S. Konidaris is an R\&D Computer Engineer. He is now doing $\mathrm{PhD}$ studies in the Computer Science and Engineering Department of Patras University. His research interests include telematics and new services, database design, implementation of managed bandwidth services and videoon-demand algorithms. He has participated in projects such as ELECTRA and ODYSSEAS and is now involved in project TODAY'S STORIES.

Afrodite V. Sevasti is an R\&D Computer Engineer, at the Computer Technology Institute, Patras, Greece. She is now doing PhD studies at the Computer Science and Engineering Department of Patras University Greece. Her research interests include telematics and new services, virtual reality services, Database design, implementation of managed bandwidth services, and video-on -demand algorithms. She has participated in R\&D projects such as ELECTRA, and ODYSSEAS and is involved in project TODAY'S STORIES. 